\title{
火力发电厂 EPC 工程设计优化管理
}

\section{Research on Optimal Management of EPC Engineering Design in Thermal Power Plant}

\author{
解贵林 \\ Guilin Xie \\ 中国华电科工集团有限公司设计院 中国・北京 100160 \\ Design Institude of China Huadian Engineering Co.,Ltd., Beijing, 100160, China
}

摘 要: 近几年来, 中国的 EPC 项目在各行各业当中都取得了较大的成绩, 尤其是在火力发电厂的建设过程当中, EPC 总承 包模式也有着举足轻重的地位, 为了能够体现技术上的优势, 就必须对 EPC 工程建设模式的各阶段设计优化的特点进行深入 分析,这样才能够更好的完善 EPC 工程设计优化管理制度,提升中国火力发电厂的 EPC 工程建设水平。

\begin{abstract}
In recent years, China's EPC projects have made great achievements in all walks of life, especially in the construction process of thermal power plants, the EPC general contracting mode also has a pivotal position. In order to reflect the technical advantages, it is necessary to conduct an in-depth analysis on the characteristics of the design optimization at each stage of the EPC project construction mode, so as to better compietely improve the EPC project design and optimize the management system and improve the EPC engineering level of China's thermal power plants.
\end{abstract}

关键词: 火力发电厂; EPC 工程;设计优化;优化管理

Keywords : thermal power plant; EPC engineering; design optimization; optimization management

DOI : 10.36012 /etr.v2i7.2226

\section{1 火力发电厂 EPC 工程的简要分析}

中国目前 EPC 项目主要是指受到工程项目的业主委 托, 按照相关的合同约定, 对整个工程项目进行设计、采购、 施工、调试以及移交运行等 ${ }^{[1]}$ 。在整个工程建设过程中, 通常 情况下工程的承包方会在总价合同条件下对整个工程的各 个环节负责, 也称作工程总承包。目前来看, EPC 模式在国家 发展以及社会各行业发展的过程当中,都有着越来越显著的 重要地位。在进行工程项目总承包的过程当中, 需要按照国 家的相关指导意见进行原则的划分, 保证工程项目的总负责 人承包整个工程的主体建筑实施, 确保工程质量, 当然还应 该配备相关单位来对相关的工作内容进行服务和监督管理, 更好地为业主和 EPC 方提供管理服务。

在整个 $\mathrm{EPC}$ 模式当中，涉及整个工程内容的总体策划 以及策划之后的各项具体工作, 包括工程设计、设备和材料 采购以及施工安装等多种问题。EPC 工程建设的首要目标是
使完工项目的各项指标都达到预期值,然后进一步在试运行 过程中不断优化,使其可以长期、安全、可靠的运行。

\section{2 进行 EPC 工程设计优化的策划方案分析}

\section{1 配备工程优化设计审查工程师}

在进行设计优化的过程当中, 必须根据不同阶段的工作 特点来采取相应的优化管理策略,这样才能够更好地保证整 个工程得以顺利实施。在这种情况下, 可以考虑为整个 $\mathrm{EPC}$ 工程配备专业的工程优化设计审查工程师。对整个电厂设计 进行充分详细且系统地了解, 然后要求设计单位按照火力发 电厂的需求设计相关的系统和设备。同时优化设计审查工程 师还应该对各展业需求的材料进行详细地了解，比如说电 气、输煤、热控等。只有这样, 专业的优化设计审查工程师才 能够更好地将理论经验体现到优化设计审查中, 确保整个优 化设计的专业性以及科学性。 


\section{2 建立优化设计审查制度}

为了能够更好地在 EPC 工程的策划过程中进行设计优 化, 就必须有一个相对完善的审查制度, 这样才能够使一切 优化设计方案得到制度的支持[2]。这就要求火力发电厂应该 根据项目的实际需求以及项目分工来完善设计审查制度, 安 排专业工程师对各专业设计方案进行全面的审查, 在审查和 优化的过程当中逐渐完善审查制度, 为所有审查行为提供根 本保障, 确保所有的行为都更加科学合理。

\section{3 建立优化设计协助审查制度}

由于火力发电厂在进行项目设计的过程当中, 优化过程 相对复杂, 而且有一些项目对科技要求较高, 对专业技术的 要求非常严格, 这就需要相关的协助审查制度来做, 单独的 优化设计审查制度并不能够对整个工程的边边角角以及各 个环节的细节做出明确的要求, 这个时候引入优化设计协助 审查制度, 可以对专业技术要求高以及科技含量高的地方做 出明确要求, 邀请更加专业的外部机构进行协助审查。

\section{3 进行工程设计优化管理的步骤分析}

\section{1 初步设计阶段的优化设计管理及实施}

在初设阶段, 由于整个工程处于前期阶段, 需要编制相 关的初步设计原则, 保证各种设计方案都在初步设计原则范 围内, 这一点是非常重要的。初步设计原则以及初步设计方 案是影响整个工程的主要前提, 因此, 在对初设原则拟定阶 段进行设计优化时, 就应该确保设计原则以及设计方案的可 靠性、安全性以及合理性。在初步设计阶段, 优化设计是详细 地了解该工程项目的各项流程, 然后对各专业设计方案进行 优化。例如, 对除氧器布置高度、锅炉给水泵配置的考虑、是 否设置锅炉上水泵、汽轮机的油净化装置是否采用大小机器 公用、发电机出线方式、输煤来煤方式等对工程影响较大方 案进行比选。当然, 在进行方案设计优化时, 还要充分考虑整 个电厂的各专业构成及相互之间的联系, 对专业交叉的内容 进行协调优化和综合考虑。

\section{2 施工图设计阶段的优化设计管理及实施}

施工图设计过程是整个流程由图纸转换为工程实体的 一个重要依据, 所以说施工图设计的合理性以及科学性是非 常重要的, 它对于整个工程的可实施性起了非常重要的作
用。为了能够更好地实现施工图图纸的优化设计审查, 就必 须对整个施工图纸设计进行严格管理, 这样才能够更好地保 证施工图体现出所有优化意见 ${ }^{[3]}$ 。在进行施工图纸设计审查 时, 火力发电厂 $\mathrm{EPC}$ 总承包方的工程技术部应该充分考虑 施工阶段以及后期运行阶段中可能存在的各种问题, 然后提 出针对性的优化设计方案, 如优化各厂房和构筑物的布置、 设备管道的布置设计, 应该尽可能地进行优化, 以满足施工 和调试运行为主要目标。

\section{3 施工阶段的优化设计管理及实施}

为了能够更好地对整个工程进行优化管理, 对施工阶段 进行优化管理是非常必要的, 这就要求工程施工方必须对整 体的设计方案有一个充分且详细地了解, 并对施工图纸进行 全方位详细的理解, 进而对其进行细部优化, 在施工阶段, 优 化设计已经到了结尾, 因此, 这个阶段的所有优化内容都应该 以满足施工过程当中的现场需求为根本关注点, 在这个过程 当中, 要注意细节布置调整、整体运行检修通道和检修实施的 调整, 当然, 在按图施工的基础上, 要尽可能达到美观的效果。

\section{4 结语}

根据以上所述内容可以看出, 目前火力发电厂 EPC 工 程在整个工程管理过程中仍然存在着诸多的问题, 为了能够 更好地保证 EPC 工程项目在执行过程当中实现项目目标并 提高盈利水平, 有必要对 EPC 工程项目建设全过程进行设 计优化, 这样可以更好地保证火力发电厂 EPC 工程在执行 过程中更加合理和高效。火力发电厂 EPC 工程可以参照本 文所进行的简要分析, 对工程设计优化管理的各个阶段进行 充分的了解, 在中国火力发电厂的 $\mathrm{EPC}$ 工程建设中逐步完 善相关设计优化管理制度, 更好地促进 EPC 工程项目管理 科学化, 提高 EPC 工程管理水平。

\section{参考文献}

[1] 于志杰,陈修贵. 火力发电厂 EPC 工程设计优化管理[J]. 国际工 程与劳务,2014(2):43-45.

[2] 何宝民. 浅谈建筑工程基础施工技术措施研究[J]. 科技创新与应 用,2013(3):210.

[3] 周声结, 郭崇晓,张燕飞. 双金属复合管在海洋石油天然气工程 中的应用[J].中国石油和化工标准与质量,2011,31(11):115116. 